Reprod. Nutr. Dévelop., 1986, 26 (1 B), 269-270.

\title{
Les choix alimentaires des bovins et ovins sur pâturages sahéliens
}

\author{
H. GUÉRIN, D. RICHARD (*), D. FRIOT, Nd MBAYE
}

Laboratoire national de l'Elevage et de Recherches vétérinaires B.P. 2057, Dakar-Hann, Sénégal.

${ }^{*}$ ) Institut d'Elevage et de Médecine vétérinaire des Pays tropicaux 10, rue Pierre Curie, 94704 Maisons-Alfort, France.

Summary. The study of the botanical composition of the diet of cattle and sheep on Sahelian pastures has been carried out with an original method, " the shepherd's collect ". It shows that the compositions of the diets and of the pastures are very different and that dietary preferences differ according to the animal species and change during the year.

Les pâturages naturels des régions sahéliennes sont composés d'espèces annuelles à cycle végétatif court et de ligneux dont l'importance est variable suivant les régions. Dans le cadre d'une recherche franco-sénégalaise sur la valeur alimentaire des fourrages disponibles au Sénégal, les compositions botaniques du pâturage et des régimes des ovins et bovins furent comparées.

Matériel et méthodes. Les observations ont été fartes dans une parcelle de 750 ha faisant partie d'un ranch de la SODESP (Société de Développement de I'Elevage en Zone sylvo-pastorale) situé à Doli dans le centre du Sénégal. La composition botanique et la production du couvert herbacé ont été étudiées sur 4 localisations non clôturées d'une surface de 2 à 4 ha (Boudet et al., 1983). Les plantes ont été déterminées régulièrement ( ${ }^{1}$ ). Le troupeau observé, composé de 15 zébus mâles âgés de 1,5 à 5 ans et de 20 béliers adultes, était conduit au pâturage sous la surveillance permanente de bergers.

Les préférences alimentaires des animaux ont été étudiées par la méthode de la " collecte du berger " (Guérin et al., 1983-1984). Elle fait appel à la bonne connaissance de la flore et du comportement des animaux qu'ont les gardiens des troupeaux. Pendant les grands repas (de $9 \mathrm{~h} 30$ à $11 \mathrm{~h} 30$ et de $15 \mathrm{~h} 30$ à

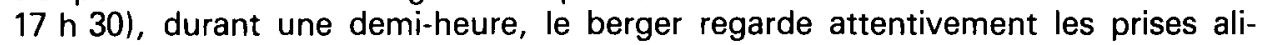
mentaires de l'animal le plus proche de lui et va prélever près du lieu de broutage une poignée de végétaux qui imite les bouchées. Les espèces présentes dans chaque "pincée " sont notées sur une fiche d'enquête. Cette méthode revient à dénombrer les contacts "bouche de l'animal-espèce végétale " par unité de temps. La collecte est renouvelée aussi souvent que possible. Le nombre de plantes citées par séance d'une demi-heure était compris entre 30 et 60 et fut d'environ 5500 pour les moutons et de 7000 pour les bovins par année. Les résultats ont été sommés mois par mois par espèce végétale (une quarantaine) puis par famille pour calculer des pourcentages.

Résultats. La biomasse disponible en début de saison sèche fut de $2000 \mathrm{~kg}$ de matière sèche (MS/ha) en 1981 et de $1300 \mathrm{~kg} \mathrm{MS} / \mathrm{ha}$ en 1982. La charge moyenne a été de $35 \mathrm{~kg}$ de poids vif/ha. La biomasse disparue au cours de la saison sèche a été pour les 2 années de $600 \mathrm{~kg}$ de $\mathrm{MS} / \mathrm{ha}$, la part effectivement ingérée par les animaux étant de l'ordre de $250 \mathrm{~kg} / \mathrm{ha}$.

La première année, les graminées étaient dominantes (fig. 1 et 2) ; l'année suivante, il y a eu une disparition presque totale des graminées à tiges et feuilles fines (Aristida mutabilis, Schoenefeldia gracilis, Eragrostis tremula) et une forte progression des légumineuses (Zornia glochidiata) et des autres herbacées (Borreria stachydea, Blepharis linariifolia). Le peuplement ligneux était à la fois peu

(1) Déterminations faites par J. Valenza, A. K. Diallo et Kh. Dieye, agropastoralistes au L.N.E.R.V. 
abondant et peu diversifié (Guiera senegalensis : 500 sujets/ha, $4 \%$ de la surface).

Les figures 1 et 2 montrent que la composition botanique des régimes ne reflètent pas celle du pâturage : les légumineuses et certaines plantes herbacées sont plus appétées que les graminées. Les choix des animaux sont cependant influencés par la composition floristique du pâturage : d'une part d'une année sur l'autre comme le montre la diminution des graminées les plus appétées entre 1981 et 1982 où une augmentation de la consommation des autres plantes a été observée, d'autre part au cours d'un cycle annuel où les préférences varient en fonction de l'appétibilité et de la disponibilité : consommation rapide des plantes les plus appétées, consommation tardive des graminées grossières. Les figures montrent également des différences importantes entre les espèces animales. Les zébus consomment toujours plus de graminées que les moutons qui recherchent les autres herbacées.
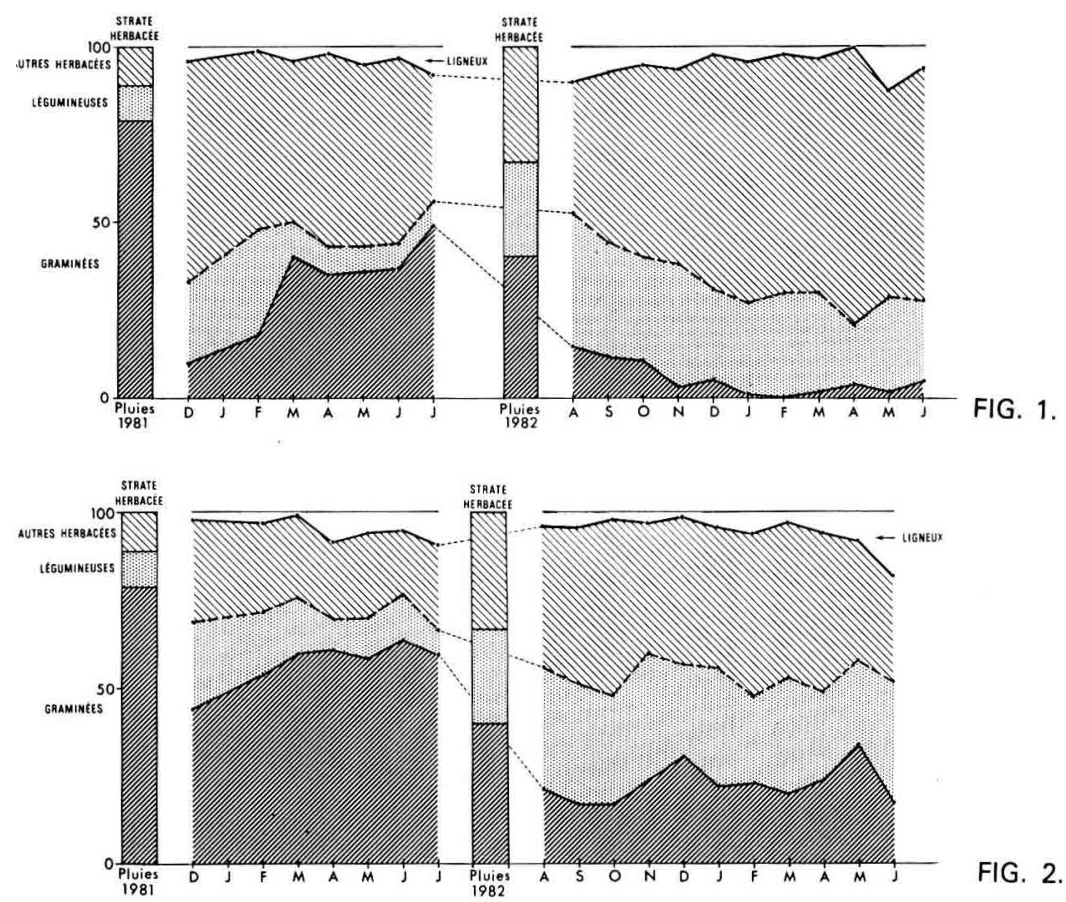

FIG. 2.

Composition botanique du pâturage et du régime alimentaire des ovins (FIG. 1) et des bovins (FIG. 2).

La méthode utilisée fournit des indications sur le rôle de chaque espèce végétale dans l'alimentation des ruminants. Elle sera comparée à d'autres méthodes (examen des bols œsophagiens et de fécès). Les résultats devraient permettre une meilleure interprétation de l'utilisation des pâturages en zone tropicale.

Boudet G., Dieye Kh., Valenza J., 1983. Environnement biotique : évolution du couvert herbacé in : Systèmes de production d'élevage au Sénégal dans la région du Ferlo. "ACC-GRIZA (LAT) "ISRA-GERDAT-ORSTOM-ORANA-OCCGE - p. 37-63.

Guérin H., Friot D., Mbaye Nd., 1983-1984. Méthodologie d'étude de la valeur alimentaire des parcours naturels à faible productivité : 1 - Approche bibliographique, LNERV, 1983, $n^{\circ} 103-31$ p. ; 2 - Protocoles et premiers résultats. LNERV, 1984, no $12-33$ p. 